\title{
EOPs
}

\section{Otoscopía neumática en el diagnóstico de Otitis Media Aguda}

\section{Caso clínico}

En un pase de residentes se discute un caso de un niño de 3 años con diagnóstico de otitis media aguda (OMA) mediante otoscopía convencional y surge la duda sobre la conveniencia de utilizar el neumatoscopio para aumentar la precisión del diagnóstico.

\section{Pregunta que generó el caso}

En niños y adultos con síntomas y/o signos compatibles con otitis media aguda (la población), la otoscopía neumática (intervención) aumenta la precisión diagnóstica de otitis media aguda (resultado) en relación con la convencional (comparación)?

\section{Búsqueda bibliográfica}

Se realizó en PUBMED (http://www.ncbi.nlm.nih.gov/entrez/ query.fcgi) y en National Guideline Clearinghouse (http://www. guidelines.gov). Se emplearon los "filtros" para limitar la búsqueda a estudios de "diagnóstico". Como palabras clave se usaron: "Otoscopía neumática", "otitis media aguda" y "efusión".

Se identificó y seleccionó un estudio que parecía ser apropiado para responder la pregunta. Se buscaron trabajos publicados desde el año 1980 hasta la fecha, en idioma inglés.

\section{Diagnóstico de otitis media}

La otitis media es una causa muy frecuente de consulta en la infancia, y representa una de las indicaciones de tratamiento antibiótico más frecuentes.

Su diagnóstico presenta un desafío para el médico, ya que là sintomatología relacionada es variada y el examen físico resulta muchas veces dificultoso de realizar, debido a diversas causas como la presencia de cerumen en el conducto auditivo externo, un niño poco cooperativo o ansiedad paterna. Estos factores pueden llevar al sobrediagnóstico y tratamiento antibiótico, con el riesgo de generar resistencia bacteriana, efectos adversos y mayores costos. A esto se agrega la controversia sobre la necesidad del tratamiento antibiótico en las otitis medias agudas, con lo cual la precisión diagnóstica adquiere una importancia fundamental.

Se define otitis media aguda a la presencia de líquido en el oído medio asociado a signos y/o síntomas de enfermedad aguda, como fiebre, otalgia, irritabilidad, síntomas respiratorios agudos, vómitos y diarrea. Los signos a evaluar para realizar el diagnóstico de otitis media aguda son el color, la posición y la movilidad de la membrana timpánica. Los dos primeros se obtienen mediante el otoscopio convencional y el tercero con la utilización de la neumatoscopía.

\section{Resumen del trabajo seleccionado}

Karma P., Markku M. et al. Pneumatic otoscopy and otitis media. Value of different tympanic membrane findings and their combinations. Am.J.Dis.Child. 1992.146(4); 433-435.

Objetivo: Evaluar la precisión de la otoscopía neumática en el diagnóstico de líquido en oído medio comparada con la miringotomía (test de referencia o gold estándar) en niños Finlandeses.

Materiales y métodos: Se realizó un seguimiento de 2911 niños Finlandeses de edades entre 6 y 30 meses, por un período de 1 a 2 años, en 2 centros de atención médica de Finlandia.

Cada vez que concurrían a alguno de los dos centros por un problema otológico, eran evaluados por un otorrinolaringólogo o un pediatra mediante otoscopía neumática. A los pacientes se les practicaba una miringotomía y aspiración. La presencia de líquido en este procedimiento era considerada diagnóstica de otitis media aguda.

De 11804 visitas registradas, 5949 fueron evaluadas por un otorrinolaringólogo y 5855 por un pediatra. Se excluyeron los oídos con timpanostomía y los que no fueron adecuadamente registrados.

El registro fue sobre el color (rojo, opaco o normal), posición (protrusión, retracción o normal) y movilidad (disminuida o normal) de la membrana timpánica. Se registró el oído con cambios más severos si la patología era bilateral. Se relacionaron los hallazgos en la membrana timpánica registrados con la presencia de líquido en oído medio por miringotomía. Se calculó la sensibilidad, especificidad y valor predictivo* de cada hallazgo y de la combinación de varios para diagnosticar liquido en oído medio.

Utilidad diagnóstica de distintas combinaciones de signos (niños con sintomas agudos)

\begin{tabular}{l|l|l|l|l|l|l|}
\hline Color & Posición & Movilidad & Sensibilidad \% & Especificidad \% & Coeficiente de Prob (LR) & Valor predictivo positivo (VPP) \\
\hline Rojo & Normal & Normal & 13,6 & 84,5 & 0,88 & $14,5 \%$ \\
\hline Opaco & Normal & Normal & 81,4 & 67,1 & 2,5 & $36,8 \%$ \\
\hline Normal & Normal & Disminuida & 76,8 & 5,3 & 5,2 & $66,7 \%$ \\
\hline Rojo & Normal & Disminuida & 76,3 & 97,1 & 26,3 & $88,6 \%$ \\
\hline Opaco & Normal & Disminuida & 92,9 & 99,2 & 116,1 & $96,8 \%$ \\
\hline Opaco & Protruida & Disminuida & 95,7 & 99,4 & 159,5 & $98,8 \%$ \\
\hline
\end{tabular}

\section{Comentario}

Según este estudio, la combinación de hallazgos otoscópicos como el color opaco, la posición protruida y la hipomotilidad aumenta el VPP para otitis media aguda en relación a signos aistados (la coloración roja aislada tiene un VPP de $14,5 \%$ mientras que si se asocia a hipomotilidad se eleva al $88,6 \%$ ). Si se compara el VPP de la coloración roja $(14,5 \%)$ con la cual muy a menudo se realiza diagnóstico, con otro signo aislado, pero de la otoscopía neumática, como la hipomotilidad (VPP 66,7\% \%), se aprecia la mayor precisión de este último signo, y si se asocian ambos hallazgos el valor trepa al $88,6 \%$ (siempre recordando que el valor predictivo depende en parte de la prevalencia).

Estos datos parecerían indicar que la utilizaciơn de la neumatoscospía aumenta el valor predictivo de los signos encontrados mediante otoscopía convencional para diagnosticar otitis media aguda en niños. Además, este estudio parece indicar que la precisión diagnóstica es mayor si se utiliza la combinación de signos otoscópicos y no uno en forma aislada. No se han encontrado traba- jos que demuestren algo similar en población adulta. Sin embargo sería posible extrapolar estos hallazgos en otitis media aguda infantil a la patotogra de tos adultos, ya que ta fisiopatogenia y signos otoscópicos son similares. Cabe destacar que en este trabajo se utilizó la miringotomía y aspiración como test de referencia para comparar la sensibilidad y especificidad de los diferentes signos otoscópicos, lo cual constituye un patrón adecuado.

\section{Conclusión}

La evidencia hallada parece ser suficiente para recomendar la realización de la neumatoscopía además de la otoscopía convencional en pacientes pediátricos con sospecha de otitis media aguda para aumentar la precisión diagnóstica. No se ha encontrado evidencia directa de la utilidad del método en adultos, pero es posible inferir que el neumatoscopio sería útil también en esta población.

* Ver glosario.

Dra. Victoria Wurcel

Unidad de Medicina Familiar y Preventiva. Hospital Italiano de Buenos Aires 